\section{P544 TRENDS IN RECREATIONAL DRUG USE AND ASSOCIATIONS WITH CAS, HIV AND STI AMONG HIV- NEGATIVE MSM IN AMSTERDAM BETWEEN 2008-2017}

${ }^{1}$ Liza Coyer*, 'Anders Boyd, ${ }^{1}$ Udi Davidovich, ${ }^{2}$ Maria Prins, ${ }^{1}$ Amy Matser. ${ }^{1}$ Public Health Service of Amsterdam, Infectious Diseases, Amsterdam, Netherlands; ${ }^{2}$ Public Health Service of Amsterdam, Amsterdam UMC, Infectious Diseases, Amsterdam, Netherlands

\subsection{6/sextrans-2019-sti.619}

Background Recreational drug use (RDU), particularly during sex, may contribute to human immunodeficiency virus (HIV) and sexually transmitted infections (STI) transmission by increasing sexual risk behaviour. We studied changes in RDU, including chemsex, and associations with condomless anal sex (CAS), HIV and STI among HIV-negative men who have sex with men (MSM).

Methods MSM enrolled in the Amsterdam Cohort Studies with $\geq 1$ study visit between 2008-2017 ( $n=887)$ were asked questions on behaviors in the preceding 6 months and underwent HIV/STI testing (chlamydia, gonorrhea, syphilis) biannually. Changes in RDU (overall/during sex) and chemsex (GHB/ GBL, mephedrone, methamphetamine, ketamine, amphetamine, cocaine and/or XTC during sex), and their associations with CAS, HIV and any STI ( $<6$ months), were tested across calendar years using logistic regression with generalized estimating equations, while adjusting for age, calendar year, country of birth and education level.

Results Of 884 included MSM, 83.5\% were born in the Netherlands and $75.3 \%$ had a college degree. Median age on 1January-2008 was $32.4(\mathrm{IQR}=24.9-38.9)$ years. Median number of visits with RDU data was 11 (IQR=5-18). RDU increased from $66.8 \%$ in 2008 to $70.0 \%$ in 2017 (2017 vs 2008: $\quad a O R=1.23, \quad 95 \% C I=1.03-1.48)$. RDU during sex increased from $52.4 \%$ in 2008 to $58.7 \%$ in 2013 (2013 vs 2008: $\quad \mathrm{aOR}=1.22,95 \% \mathrm{CI}=1.05-1.42)$ and remained stable afterwards. Chemsex increased from $19.3 \%$ in 2008 to $23.6 \%$ in 2017 (2017 vs 2008: $\mathrm{aOR}=1.52,95 \% \mathrm{CI}=1.21-1.90)$. Among those with a reported sex partner, RDU during sex was associated with CAS $(\mathrm{aOR}=1.33,95 \% \mathrm{CI}=1.17-1.52)$, HIV $(\mathrm{aOR}=7.92,95 \% \mathrm{CI}=2.75-22.8)$, and STI $(\mathrm{aOR}=2.31$, $95 \% \mathrm{CI}=1.92-2.77)$. Chemsex was associated with CAS $(\mathrm{aOR}=1.54, \quad 95 \% \mathrm{CI}=1.32-1.79), \quad \mathrm{HIV} \quad(\mathrm{aOR}=6.46, \quad 95 \%$ $\mathrm{CI}=3.48-12.0)$, and STI $(\mathrm{aOR}=2.29,95 \% \mathrm{CI}=1.88-2.76)$.

Conclusion Slight increases in RDU and chemsex were found over time among HIV-negative MSM in Amsterdam and were strongly associated with CAS, HIV and STI. Effective interventions to reverse these trends in RDU are needed.

Disclosure No significant relationships.

\section{P545 TRENDS IN HIV INFECTION AND AIDS IN MEN WHO HAVE SEX WITH MEN (MSM): ADULTS COMPARED TO YOUNG PEOPLE IN SAO PAULO, BRAZIL}

Mariza Tancredi, Valdir Pinto, Ângela Tayra, Marcia Polon, Carmen Silvia Domingues*. STI/ AIDS Reference Center - Sao Paulo State Program of STI/AIDS, Sao Paulo Department of Health, Sao Paulo, Brazil

10.1136/sextrans-2019-sti.620

Background The objective was to analyze the trends of AIDS cases and HIV infection cases among man who have sex with man (MSM) adults versus young people (15-24 years old) in the period from 2007 and 2017.
Methods A trend study using polynomial regression models carried out with AIDS cases and HIV+ cases compared among MSM adults and young people (15-24 years old) in the period from 2007 to 2017. The annual number of AIDS cases and HIV+ cases was considered as the dependent variable $(\mathrm{Y})$, regarding the studied categories, and time was the independent variable $(\mathrm{X})$, represented by calendar years. The goodness of fit via $\mathrm{r}^{2}$ and $\mathrm{p}<0.05$ were used to determine which models and data were most appropriate.

Results 88,025 AIDS cases were analyzed versus 70,753 HIV+ cases in adult men. For AIDS cases a decreasing trend was observed with first-order modeling $[\mathrm{Y}=-205 \mathrm{x}+9,235$; $\left.\mathrm{r}^{2}=0.83 ; \mathrm{p}=0.039\right]$; however for HIV + the trend was increasing $\left[Y=547 x+3,147 ; r^{2}=0.95 ; p<0.001\right]$. Adult MSM with AIDS $(n=20,837)$ versus HIV+ $(\mathrm{N}=30,594)$ were selected. For MSM-AIDS, a significant difference with increasing tendency was observed $\left[\mathrm{Y}=47 \mathrm{x}+1,614 ; \mathrm{r}^{2}=0.58 ; \mathrm{p}=0.050\right]$ and for MSM-HIV+ the trend was increasing, but with higher growth rate $\left[391 \mathrm{x}+430 ; \mathrm{r}^{2}=0.97 ; \mathrm{p}<0.001\right]$. Young MSM (15-24yo) with AIDS ( $N=3,734)$ versus HIV+ $(\mathrm{N}=10,185)$ were selected. For young MSM-AIDS, there was an increasing tendency $\left[Y=28 \mathrm{x}+172 ; \mathrm{r}^{2}=0.81 ; \mathrm{p}=0.036\right]$ and for young MSM-HIV+ the tendency was increasing and with a higher rate $\left[155 \mathrm{x}-8 ; \mathrm{r}^{2}=0.96 ; \mathrm{p}<0.001\right]$.

Conclusion The total number of cases of HIV+ men exceeded AIDS cases in 2014. However, among MSM-HIV+, the overcoming point was earlier in 2010, and among young people the overcoming point was earlier, before 2007. Among the MSM the trends of HIV and AIDS infection are markedly increasing among young people, highlighting the greater vulnerability of young MSM in Brazil in need of early HIV testing and timely treatment.

Disclosure No significant relationships.

\section{P546 "STIS ARE EVERYONE'S RESPONSIBILITY": A NEW CONCEPTUAL MODEL OF SEXUAL HEALTH AMONG GAY AND BISEXUAL MEN}

${ }^{1}$ Denton Callander*, ${ }^{2}$ Steven Philpot, ${ }^{3}$ Limin Mao, ${ }^{4}$ Brent Mackie, ${ }^{5}$ Tim Duck, ${ }^{6}$ Craig Cooper, ${ }^{4}$ Matthew Vaughan, ${ }^{7}$ Shih-Chi Kao, ${ }^{2}$ Larissa Lewis, ${ }^{2}$ Basil Donovan, ${ }^{8}$ Chris Bourne. ${ }^{1}$ New York University, School of Medicine, New York, USA; ${ }^{2}$ UNSW Sydney, Kirby Institute, Sydney, Australia; ${ }^{3}$ UNSW Sydney, Centre for Social Research in Health, Sydney, Australia; ${ }^{4}$ ACON, Sydney, Australia; ${ }^{5}$ New South Wales Ministry of Health, Sydney, Australia; ${ }^{6}$ Positive Life New South Wales, Sydney, Australia; ${ }^{7}$ Sydney Local Health District, Sydney, Australia; ${ }^{8}$ NSW Health, NSW STI Programs Unit, Surry Hills, Sydney, Australia

\subsection{6/sextrans-2019-sti.621}

Background Around the world, rates of sexually transmissible infections (STIs) continue to rise among gay and bisexual men. To respond to these increases, information is needed on the sociocultural realities underpinning prevention and management among at-risk populations, including gay and bisexual men.

Methods In mid-2018, qualitative data were collected from an Australian sample of gay men via a moderated online discussion forum $(n=35)$ and in-depth interviews with forum participants $(n=5)$ and sexual health physicians $(n=4)$. An inductive thematic analysis was undertaken.

Results First, gay men and sexual health physicians mostly agreed that STIs should be a normalised, de-stigmatised aspect of sexuality. Second, many participants felt that STI prevention and management should be individualised, tailored to individual need and preference. Third, participants desired a holistic 